\title{
Developments in Studies on Cross-Border Mergers and Acquisitions, 1996-2011
}

\section{Samra Chaudary ${ }^{*}$ and Saad Shahid ${ }^{* *}$}

\begin{abstract}
This paper analyzes the methodological and publication trends in the literature on cross-border mergers and acquisitions over three five-year periods, 1996-2001, 2001-06, and 2006-11. Based on a selection of 23 journals and a sample of 170 articles, we use advanced cross-tabulations to study the publication and methodological trends that have emerged in North America, Europe, and other regions. Our main findings are as follows. A+-rated journals tend to accept the use of regression as a key technique. Top-tier journals accept papers primarily in finance and accounting and international business. Researchers' interest in international business has increased at a rising rate, and increased at a falling rate in finance and accounting. The publication of conceptual quantitative articles has increased significantly by 45 percent over the 15-year period. About 98 percent of the total sample uses modeling as a methodology and is accepted by A+- and A-rated journals. Cross-sectional studies are more popular than longitudinal studies. The financial institutions industry has been studied the most in all parts of the world and at an increasing rate over the period under review. Researchers' interest in manufacturing industries has, however, declined over the 15 years in all regions.
\end{abstract}

Keywords: Cross-border mergers and acquisitions, content analysis, methodological developments, publication developments.

\section{JEL classification: G34.}

\section{Introduction}

Mergers and acquisitions (M\&A) are a universal phenomenon with companies acquiring targets all over the world. Datta, Pinches, and Narayanan (1992) define mergers as "negotiation directly with the target firm's management and/or the board of directors and approved by them before going to a shareholder vote." Cross-border acquisitions are a vehicle for rapid development across national boundaries (see Hitt,

\footnotetext{
* The author is a teaching fellow in finance (corresponding author) at the Lahore School of Economics and can be contacted atch.samra@gmail.com.

** The author is a teaching fellow in marketing at the Lahore School of Economics and can be contacted at saadshahid9@gmail.com.
} 
Hoskisson, \& Kim, 1997; Hitt, Harrison, Ireland, \& Best, 1998; Nadolska \& Barkema 2007). Global M\&A activity in 2006 was USD 3.8 trillion-an increase of 37.9 percent compared to 2005 to a sum of 36,958 deals (Bernad, Fuentelsaz, \& Gómez, 2010).

There is, however, a very limited body of M\&A literature (Meglio \& Risberg, 2010) and few studies have examined cross-border acquisitions as a group (see Haleblian, Kim, \& Rajagopalan, 2006; Hitt, Ireland, \& Harrison, 2001). This is one of the weaknesses of the existing M\&A literature. To our knowledge, this article is the first systematic literature review of trends seen in the 15-year period 1996-2011. We take a sample of 170 conceptual quantitative journal articles on cross-border M\&A. Our study tries to fill this gap in the literature and has three main objectives: (i) to analyze the publication trends in cross-border M\&A research published from 1996 to 2011, (ii) to identify patterns in the methodological developments in the literature, and (iii) to suggest future directions for research based on our findings in the domain of cross-border M\&A.

The remaining article is organized as follows. Section 2 presents a literature review that highlights the dearth of studies in this area. Section 3 defines the study's research questions. Section 4 describes the methodology used, sample selection, and coding with validity. Section 5 discusses the results and their implications. Section 6 concludes the study.

\section{Literature Review}

The dearth of literature on cross-border M\&A is highlighted by Meglio and Risberg (2010), which is the only study closest to our research. The authors discuss the advantages and disadvantages of methodologies used in M\&A studies. They advocate real-time longitudinal research because cross-sectional research has the drawback of relying on secondary

data. Moreover, most existing M\&A studies involve hypothesis and correlation testing. Haleblian, Devers, McNamara, Carpenter, and Davison (2009) find that the majority of acquisition research is cross-sectional and focuses on US corporations, using mainly quantitative secondary data, given the proliferation of databases. Generally, longitudinal M\&A studies have been found to last four years (Greenwood, Hinings, \& Brown, 1994).

Although studies on M\&A efficiency have been published in toptier management journals from 1970 onward (Meglio \& Risberg, 2009), M\&A scholars have shown little interest in qualitative research because of the scarcity of real-time studies; many of them are grounded in strategy or finance. Haleblian et al. (2006) and Hitt et al. (2001) focus on international 
acquisition and conclude that only a small number of studies have examined cross-border acquisitions as a group.

Notably, Ellis, Moeller, Schlingemann, and Stulz (2011) find that M\&A gains are determined by international factors or at least by country factors. Across all acquisitions, the acquisition year and the acquirer's industry generally explain the stock-price response better than the acquirer's country. Hence, we analyze time horizon, country, and industry to explore these trends.

As a unique literature review of cross-border M\&A, we base our findings on a number of factors including the research methods used, respondent type, sample size, and statistical techniques. We also address the limitations and illustrate trends in the literature with respect to these factors across time and various geographical regions.

\section{Research Questions}

The study's research questions are as follows:

1. What developments have taken place in publication trends over the three five-year periods under review (1996-2011)?

2. What developments have taken place in methodological trends over the three five-year periods under review (1996-2011)?

3. What are the key criteria (in terms of methodology) that determine publication in top-tier journals?

\section{Methodology and Sample Selection}

This section describes the methodology and sample used.

\subsection{Content Analysis Methodology}

This study uses a content analysis methodology to analyze developments in the publication of M\&A literature over the period 19962011. Kolbe and Burnett (1991) define content analysis as a research technique that is used to systematically appraise the symbolic content of all types of documented communication. It has also been explained as "any methodological measurement applied to text (or other symbolic materials) for social science purposes" (Shapiro \& Markoff, 1997). 
Content analysis has an edge over other qualitative methods such as literary interpretation and hermeneutics because it includes a qualitative as well as quantitative component (Duriau, Reger, \& Pfarrer, 2007). It also helps researchers "step back from their individual trees in order to access the entire forest of knowledge generation within a discipline" (Williams \& Plouffe, 2007). Content analysis is useful in analyzing secondary data because it helps reduce events into defined categories for better understanding (Harwood \& Garry, 2003). Datta et al. (1992) argue that content analysis is particularly appropriate when a substantial body of empirical evidence is available.

In the preliminary sample selection process, we used the Science Direct database, which comprises 23 journals rated by Anne-Wil Harzing's Erasmus Journal Listing for April 2012. The keywords applied were "crossborder mergers and acquisitions" and "international mergers and acquisitions." The time period under review was divided into three fiveyear periods, 1996-2001, 2001-06, and 2006-11, similar to Page and Schirr (2008). Our analysis is restricted to trends in journal articles.

Initially, the total number of articles analyzed was 7,249. The articles were downloaded and tabulated in RefWorks and Microsoft Excel. RefWorks was used to export and save the search results from Science Direct into Microsoft Excel under various headings. Any duplicate data was deleted and only the necessary headings, i.e., each article's unique identification number, author (primary and secondary), title, publication year, and journal name were recorded. Out of 7,249, only 205 articles were relevant to cross-border M\&A.

Table A1 (Annex) lists the journals that were sampled and indicates their ratings and the percentage of articles selected from each. The 205 relevant articles include empirical quantitative, empirical qualitative, and conceptual quantitative studies, but we have further restricted our analysis to 170 conceptual quantitative studies that use quantitative data or quantitative models.

It is important at this point to differentiate between empirical and conceptual research and between quantitative and qualitative research. Minor, Hensley, and Wood (1993), Aulakh and Kotabe (1993), and Dangayach and Deshmukh (2001) categorize research as either empirical or conceptual, while Li and Cavusgil (1995) classify it as either qualitative or quantitative. A qualitative study draws on socially observable facts based on words and performed in natural settings (Creswell, 1994; Plewis \& Mason, 
2005). Creswell (1994) defines a quantitative study as "composed variables, measured with numbers, and analyzed with statistical procedures."

Taking this further, Nakata and Huang (2005) and Page and Schirr (2008) propose four types of research: empirical quantitative, empirical qualitative, conceptual quantitative, and conceptual qualitative. Conceptual quantitative studies use quantitative data or quantitative models. Empirical qualitative studies use primary data, i.e., data collected through interviews, surveys, and observations (Workman, 1993). Empirical quantitative studies also use primary data but their findings are based on statistical analysis.

The relevant criteria for the final sample of articles were developed based on their abstracts. If the abstract alone did not adequately establish the study's relevance to cross-border M\&A, the entire article was read. Advanced cross-tabulations were used to identify any methodological and publication trends in cross-border M\&A. Table 1 gives the total number of studies and relevant studies.

Table 1: Total number of studies

\begin{tabular}{lcc}
\hline Period & Total number of articles found & Total number of relevant articles \\
\hline $1996-2001$ & 1,516 & 32 \\
$2001-2006$ & 2,058 & 68 \\
$2006-2011$ & 3,675 & 105 \\
\hline Total & $\mathbf{7 , 2 4 9}$ & $\mathbf{2 0 5}$ \\
\hline
\end{tabular}

\subsection{Coding with Agreement}

The final sample of 170 articles was read and coded for a period of inquiry starting from 1996 to 2011. Content analysis advocates coding to reduce the data and make it systematic and comparable by developing different classifications (Berg, 2004). All the data categories were defined, after which the data was entered and cleaned. The articles in the final sample were evaluated autonomously. Any differences of opinion that emerged while coding the articles were resolved based on the key terms used and a joint reassessment of the article in question.

In order to analyze trends in methodological developments, each article was coded based on the following 12 dimensions:

1. Research design 
2. Sample size

3. Industry type

4. Statistical technique

5. Data source

6. Time frame: cross-sectional or longitudinal

7. Reliability, validity, and robustness estimates

8. Number of databases used

9. Number of years analyzed

10. Year data was collected minus year in which study was published

11. Country studied

12. Number of countries studied

Similarly, in order to analyze publication trends, each article was coded based on the following seven dimensions:

1. Discipline (Harzing's 2012 listing)

2. Number of authors

3. Location of authors

4. Number of institutions

5. Authorship type (academic/practitioner)

6. Number of authors' countries

7. Journal rating (Harzing's 2012 listing)

\subsection{Reliability of Coding}

Cohen's kappa was computed for 10 percent of the total sample based on two dimensions for all 170 articles. We obtained kappa coefficients of 0.87 and 0.85 , respectively. Cohen's kappa is an index of inter-rater agreement between coders that controls for chance agreement, unlike percentage agreement (Cohen, 1960). The sample was coded by two independent coders, who, at the time of coding, were management doctoral students and had successfully completed their research methods and statistics coursework. The coders received an hour's training in coding procedures. A kappa value above 0.70 indicates acceptable interrater agreement (Miles \& Huberman, 1994). Differences of opinion 
between the two coders were resolved in conjunction with one of the authors. The coding process thus followed the rigorous procedure suggested by Duriau et al. (2007).

\section{Results}

Our analysis is divided into two main categories: publication trends and methodological developments. Of the total sample, 83 percent of the articles were classified as conceptual quantitative and the remaining 17 percent as empirical quantitative or empirical qualitative. We observed that the number of conceptual quantitative articles increased during 1996-2001 by 15 percent, in $2001-06$ by 25 percent, and in 2006-11 by 60 percent.

\subsection{Publication Trends}

This section provides a systematic quantitative review of publication trends in cross-border M\&A studies, based on our sample of 170 conceptual quantitative articles.

We find that 52 percent of the authors are located in North America, 32 percent in Europe, and 16 percent in areas other than North America and Europe (referred to as "other"). Nakata and Huang (2005) present similar findings, indicating that US-based researchers dominate the literature: they produce roughly two thirds of the articles (61 percent) published, either as single authors or co-authors (academics and practitioners). However, 2001 onward, authors in North America and Europe seem to increase at a decreasing rate, while those located in other parts of the world such as China and Japan increase at an increasing rate. This change could be attributed to increased M\&A activity in China and Japan. Prather and Rueschhoff (1996) also suggest that authors' collaborations across different countries generate better-quality research than coauthors from the same country.

We observe that A-rated journals publish articles by academics and practitioners as well as collaborative articles by both (see Figure A1 in the Annex). About 55 percent of A-rated and 11 percent of A+-rated journals publish articles written in collaboration. Studies on cross-border M\&A are accepted frequently by top-tier journals as opposed to unrated or unreported ones. Meglio and Risberg (2009) present similar findings for top-tier management journals from 1970 to date.

Analyzing research type against journal ratings, we find that 57 percent of A-rated and 24 percent of B-rated journals accept conceptual 
quantitative studies on cross-border M\&A. However, this figure is only 11 percent for A+-rated journals. Analyzing discipline against journal ratings, we find that 90 percent of A-rated journals prefer studies in finance and accounting. This implies that top-tier journals prefer finance and accounting articles primarily because they are quantitative studies. Figure A2 in the Annex shows that most research is carried out in finance and accounting and in international business.

2001 onward, studies in international business increase at a decreasing rate while those in finance and accounting increase at an increasing rate. This trend is expected to continue: Figure A3 in the Annex shows that top-rated journals tend to accept M\&A studies in this discipline, indicating that researchers are more likely to work in finance and accounting and in international business.

From 1996 to 2011, finance and accounting gain pace among researchers with an increase from 9 percent to 43 percent over 15 years. This can be attributed to the preference of top-tier journals for publishing articles in finance and accounting. Although studies in international business also increase at an increasing rate, this increase occurs only for Brated journals. The popularity of publication in B-rated journals can be attributed to the scarcity of real-time studies.

Articles coauthored by two and three researchers show an increasing trend. Between 1996 and 2011, the incidence of two authors per study increases continuously from 6 percent to 27 percent, while that of three authors per study increases from 6 percent to 24 percent. The incidence of four or more authors declines between 2001 and 2006. The increase in two authors per study can be attributed to top-tier journals' acceptance of collaborations.

Next, we analyze trends in the number of coauthors (two and three authors per study) against region (see Figure A4 in the Annex). Twoauthor studies increase from 45 percent to 79 percent between 1996 and 2001, along with research on Europe, but decline between 2001 and 2011, along with research on North America. The trend in three authors per study is similar for North America and Europe over the period 1996-2011, declining between 1996 and 2001 and then increasing from 2001 to 2011.

Authors located in regions other than North America and Europe comprise 16 percent of the sample-a substantial proportion when compared with North America and Europe. This implies that top-tier 
journals publish articles by authors from other parts of the world, including those working in finance and accounting and in international business. Table 2 gives the simple averages of indicators relevant to the sample of 170 conceptual quantitative articles.

Table 2: Simple mean averages of dimensions studied for 170 conceptual quantitative articles

\begin{tabular}{lc}
\hline Indicator & Average \\
\hline Sample size & 2,572 \\
Number of countries studied & 12 \\
How old is the data? (years) & 18 \\
Number of data sources & 3 \\
Number of authors' countries & 1 \\
Number of authors per study & 2 \\
Number of years studied & 12 \\
\hline
\end{tabular}

Overall, our findings on publication trends will help researchers determine which important factors to consider in order to increase their chances of being published in top-tier journals. These factors include: (i) conceptual quantitative studies in finance and accounting and international business, (ii) work carried out in collaboration, and (iii) two authors per study. The data shows that conceptual quantitative studies comprise 83 percent of the 206 shortlisted articles. Post-2001, A+-rated and A-rated journals show an increased rate of acceptance for research conducted in finance and accounting and international business. The rate of collaboration between academics and practitioners also increases after 2001, implying a rise in the importance of integrating the knowledge base on the academic and applied sides.

\subsection{Methodological Developments}

This section analyzes the methodological developments that have taken place in our sample of 170 conceptual quantitative studies over the three five-year periods. We cross-tabulate our analysis with journal ratings to further investigate the developments in cross-border M\&A studies.

Figure A5 in the Annex shows that 70 percent of the data collected for conceptual quantitative studies on cross-border M\&A is from databases, 11.2 percent is from banks, and the smallest amount is collected from international organizations and websites. We presume this is because 
collecting international data is more difficult than domestic or publicly available data. Similarly, Figure A6 shows that most data collection relies on the use of databases. In 1996, 35 percent of the data collected was from databases compared with 59 percent after 2006. The contribution of indexes, e.g., the FTSE, NYSE, NASDAQ, and S\&P, declined from 28 percent in 1996 to 7 percent in 2006, possibly because databases have become more easily available and already include the data provided by such indexes.

Sample sizes (500 or above) are seen to increase over 1996-2011. Studies using one to three databases use larger samples (301-500 or more) than those that draw on more than three databases. Ideally, the greater the number of databases, the larger should be the sample. However, we find the opposite: studies using seven databases tend to use a sample of 0-100. Further analysis shows that A-rated journals prefer studies that use one to three databases, increasing from 36 percent to 53 percent between 1996 and 2011. The number of years studied (time period analyzed) in articles on cross-border M\&A decreases between 1996 and 2011, while the sample size increases to 500 and above. Hence, the number of years studied decreases with a parallel increase in sample size.

Top-tier journals tend to publish articles that are based on modeling as a research design. This trend increases by 22 percentage points for Arated journals between 1996 and 2001, after which it declines by 5 percentage points. B-rated journals, on the other hand, decline by 29 percentage points to 19 percent between 1996 and 2001, after which their preference for studies that use modeling increases by 6 percentage points. A+-rated journals show a remarkable preference for research that incorporates modeling, with the trend increasing by 13 percentage points from 1996 to 2011.

Regression emerges as the most popular statistical technique used, accounting for 75 percent among academics, 7 percent among practitioners, and 17 percent among collaborators. Blalock (1969) presents similar findings and argues that regression coefficients are the law of the social sciences. Meglio and Risberg (2010), however, find that most M\&A research uses correlation testing as the main statistical technique. Figure A7 in the Annex presents the overall distribution of statistical techniques used in our sample of 170 studies. Figure A8 in the Annex shows that, over the years, the use of descriptive statistics increases to 24 percent, with regression increasing from 12 percent to 36 percent between 1996 and 2011. This noticeable rise could be attributed to top-tier journals' growing preference for regression-based research. 
We also find that 12 percent of the sample studies are longitudinal and 88 percent are cross-sectional; Haleblian et al. (2009) present similar results. The bulk of M\&A research is cross-sectional and focuses on large publicly traded US corporate entities, using mainly quantitative secondary data (Haleblian et al., 2009). On average, longitudinal M\&A studies have a four-year time horizon (Greenwood et al., 1994).

Our results show that 45 percent of the sample articles focus on financial institutions. The overall distribution of this focus is such that, between 2006 and 2011, 18 percent of the research concerned North America and 15 percent analyzed the financial industry in Europe. "Other" regions accounted for 13 percent from 2006 to 2011. This implies that the financial industry has received the most attention in the last 15 years and at an increasing rate.

Figure A9 in the Annex shows that studies on the European financial industry increased from 8 percent to 15 percent between 1996 and 2006. Other regions also show an increasing trend-from 2 percent to 13 percent between 1996 and 2011. Studies on North America follow a similar trend, increasing from 4 percent to 18 percent from 1996 to 2001. Figure A9 also shows that only 4 percent of the sample articles focus on the telecommunications industry. Although no research was conducted on the North American telecommunications industry between 1996 and 2006, we do note a significant increase of 25 percent from 2006 to 2011.

Other regions follow a similar trend, with the percentage rising from 0 to 25 percent from 1996 to 2011. Europe shows an increase from 8 percent to 33 percent in this period. Overall, the telecommunications industry emerges as an area of research in all regions over the three fiveyear periods. It is useful to note that M\&A activity in Europe rose substantially because of the continuous increase in GDP per capita from USD 19,535.31 in 1996 to USD 34,923.04 in 2011.

Figure A10 in the Annex shows that researchers' interests have shifted to financial institutions and telecommunications from technology and manufacturing firms. This trend applies to all three regions. In North America, research on technology increased from 1 to 2 percent between 1996 and 2011, while that on manufacturing firms declined from 2 to 1 percent. In Europe, research on manufacturing firms also declined from 2 to 1 percent in this period. In other regions, research on technology firms declined from 3 to 2 percent and that on manufacturing firms declined from 2 to 1 percent over 2001-11. 
We find that all three types of authorship-academics, practitioners, and collaborators-prefer to carry out research on the financial industry, accounting for 44 percent, 88 percent, and 86 percent of their categories, respectively. Studies that report the robustness of their results increase from 19 percent to 70 percent over 1996-2011, although the methods used to determine robustness are not given. Studies reporting the reliability and validity of their results follow an increasing trend from 1996 to 2001, after which the trend declines. The number of years studied decline over time, but this is offset by the use of larger samples. Researchers now prefer using a 0-10-year period rather than 15 years or more. This is especially true after 2001, when we see a marked increase in the use of 0-5-year studies, i.e., from 22 percent to 55 percent.

\subsection{Discussion}

Our aim is to assess the following: (i) publication patterns in crossborder M\&A studies, (ii) methodological developments over the period 1996-2011, (iii) the key criteria that determine publication in top-tier journals, and (iv) suggestions for future areas of research on cross-border M\&A. Our results show that the bulk of cross-border M\&A studies are produced by US-based researchers-a trend that is expected to continue because the acquisition activity in a particular country offers more scope for knowledge and is more likely to produce a momentum in research (Collins \& Hitt, 2006). Further, it implies that M\&A studies in the US will increase, given the low information cost.

The publication of conceptual quantitative articles has increased significantly (by 45 percent) over 15 years, with a growing focus on financial institutions and the telecommunications industry. Post-2001, however, "other" industries appear to have received more attention.

The results for publication and methodological trends indicate that the following characteristics determine publication in top-tier journals: conceptual quantitative studies, especially in finance and accounting and international business; the use of modeling as a methodology and regression as a statistical technique; work carried out in collaboration; and two authors per study. Aulakh and Kotabe (1993) and Sin, Cheung, and Lee (1999) stress on the importance of collaborative studies across national boundaries, which, they argue, also bring in complementary skills.

What do these findings imply for academics and practitioners? First, the study has analyzed a large number of published journal articles 
(170). Second, the large sample size helps in developing meaningful conclusions about cross-border M\&A. Third, this study is the first in its field to synthesize research findings on the methodological developments and publication trends in cross-border M\&A studies. Finally, it helps identify important attributes that account for publication in top-tier journals. Unfortunately, there are no other content analysis-based studies on cross-border M\&A with which we can compare our results; this demonstrates the need for further research on M\&A activity.

\subsection{Limitations and Future Scope}

To the best of our knowledge, this is the first content analysis of cross-border M\&A, which limits the ability to generalize our findings. Generalizing the results would require replication of this study using the same methodology. This would allow researchers to determine whether our results can be generalized under a different framework. Future research could also focus on more than one database. We have relied on one database-Science Direct-for the sample selection, which is a sufficiently comprehensive source of business articles. However, the article weights are not homogenous for each journal, which may have biased the results.

There are several important avenues for further research in this area. The results show that cross-sectional studies are more popular than longitudinal ones in cross-border M\&A research primarily because the latter are time-consuming. One contribution of this study is that it assesses the requirements of editors and editorial boards, who have a crucial role to play in determining what is published in journals. Their preference for cross-sectional studies over in-depth qualitative inquiries appears to be an obstacle for real-time (longitudinal) studies. To improve the quality of research, serious reflection is needed within the academic community, including editors, reviewers, scholars, and universities.

Although this study analyzes the publication and methodological trends in cross-border M\&A research over three five-year periods, there is scope for future research on trends across three decades. Another avenue for research is the inclusion of empirical quantitative and qualitative studies in the sample; this would help researchers analyze trends in primary data on cross-border M\&A and make it easier to generalize their findings. Future research could also be directed toward analyzing trends in authorship collaboration, methodology, databases, and topics. 


\section{Conclusion}

The aim of this study has been to show which methodological developments and publication trends characterize research on cross-border M\&A and to identify potential directions for further research. Meglio and Risberg (2010) conclude that it is complicated, if not ambiguous, to identify the impact of M\&A over a short period, and suggest using other methodologies than those currently used. This paper fills a gap in the literature by helping researchers interested in cross-border M\&A assess which critical factors determine publication in top-tier journals. 


\section{References}

Aulakh P. S., \& Kotabe, M. (1993). An assessment of theoretical and methodological development in international marketing: 19801990. Journal of International Marketing, 1(2), 5-28.

Berg, B. L. (2004). Qualitative research methods for the social sciences (5th ed.). Boston, MA: Pearson.

Bernad, C., Fuentelsaz, L., \& Gómez, J. (2010). The effect of mergers and acquisitions on productivity: An empirical application to Spanish banking. Omega, 38, 283-293.

Blalock, H. M., Jr. (1969). Theory construction. Englewood Cliffs, NJ: Prentice-Hall.

Cohen, J. (1960). A coefficient of agreement for nominal scales. Educational and Psychological Measurement, 20, 37-46.

Collins, J. D., \& Hitt, M. A. (2006). Leveraging tacit knowledge in alliances: The importance of using relational capabilities to build and leverage relational capital. Journal of Engineering and Technology Management, 23(3), 147-167.

Côté, L., Langley, A., \& Pasquero, J. (1999). Acquisition strategy and dominant logic in an engineering firm. Journal of Management Studies, 36(7), 919-952.

Creswell, J. W. (1994). Research design: Qualitative and quantitative approaches. Thousand Oaks, CA: Sage Publications.

Dangayach, G. S., \& Deshmukh, S. G. (2001). Manufacturing strategy: Literature review and some issues. International Journal of Operations and Production Management, 21(7), 884-932.

Datta, D. K., Pinches, G. E., \& Narayanan, V. K. (1992). Factors influencing wealth creation from mergers and acquisitions: A meta-analysis. Strategic Management Journal, 13(1), 67-84.

Duriau, V. J., Reger, R. K., \& Pfarrer, M. D. (2007). A content analysis of the content analysis literature in organization studies: Research themes, data sources, and methodological refinements. Organizational Research Methods, 10, 5-34. 
Ellis, J., Moeller, S. B., Schlingemann, F. P., \& Stulz, R. M. (2011). Globalization, governance, and the returns to cross-border acquisitions (Working Paper No. 16676). Cambridge, MA: National Bureau of Economic Research.

Greenwood, R., Hinings, C. R., \& Brown, J. (1994). Merging professional service firms. Organization Science, 5(2), 239-257.

Haleblian, J., Devers, C. E., McNamara, G., Carpenter, M., \& Davison, R. B. (2009). Taking stock of what we know about mergers and acquisitions: A review and research agenda. Journal of Management, 35(3), 469-502.

Haleblian, J., Kim, J.-Y., \& Rajagopalan, N. (2006). The influence of acquisition experience and performance on acquisition behavior: Evidence from the US commercial banking industry. Academy of Management Journal, 49(2), 357-370.

Harwood, T. G., \& Garry, T. (2003). An overview of content analysis. Marketing Review, 3, 479-498.

Hitt, M. A., Harrison, J. S., Ireland, R. D., \& Best, A. (1998). Attributes of successful and unsuccessful acquisitions of US firms. British Journal of Management, 9, 91-114.

Hitt, M. A., Hoskisson, R. E., \& Kim, H. (1997). International diversification: Effects on innovation and firm performance in product-diversified firms. Academy of Management Journal, 40, 767798.

Hitt, M. A., Ireland, R. D., \& Harrison, J. S. (2001). Mergers and acquisitions: A value creating or value destroying strategy? In M. A. Hitt, J. S. Harrison, \& E. Freeman (Eds.), Handbook of strategic management. Oxford, UK: Blackwell.

Kolbe, R., \& Burnett, M. (1991). Content-analysis research: An examination of applications with directives for improving research reliability and objectivity. Journal of Consumer Research, 18(2), 243-250.

Li, T., \& Cavusgil, S. (1995). A classification and assessment of research streams in international marketing. International Business Review, $4(3), 251-277$. 
Meglio, O., \& Risberg, A. (2009, May). The MEA performance construct: A critical analysis. Paper presented at the 9th European Academy of Management Conference, Liverpool, UK.

Meglio, O., \& Risberg, A. (2010). Mergers and acquisitions: Time for a methodological rejuvenation of the field? Scandinavian Journal of Management, 26(1), 87-95.

Meyer, K. E., \& Lieb-Dóczy, E. (2003). Post-acquisition restructuring as evolutionary process. Journal of Management Studies, 40(2), 459-482.

Miles, M. B., \& Huberman, A. M. (1994). Qualitative data analysis: An expanded sourcebook. London, UK: Sage.

Minor, E., Hensley, R. L., \& Wood, R. D., Jr. (1993). A review of empirical manufacturing strategy studies. International Journal of Operations and Production Management, 14(1), 5-25.

Nadolska, A., \& Barkema, H. G. (2007). Learning to internationalize: The pace and success of foreign acquisitions. Journal of International Business Studies, 38, 1170-1186.

Nakata, C., \& Huang, Y. (2005). Progress and promise: The last decade of international marketing research. Journal of Business Research, 58, 611-618.

Page, A. L., \& Schirr, G. R. (2008). Growth and development of a body of knowledge: 16 years of new product development research 19892004. Journal of Product Innovation Management, 25, 233-248.

Plewis, I., \& Mason, P. (2005). What works and why? Combining quantitative and qualitative approaches in large-scale evaluations. International Journal of Social Research Methodology, 8(3), 185-194.

Prather, J., \& Rueschhoff, N. (1996). An analysis of international accounting research in US academic accounting journals, 19801993. Accounting Horizons, 10(1), 1-17.

Shapiro, G., \& Markoff, J. (1997). A matter of definition. In C. W. Roberts (Ed.), Text analysis for the social sciences: Methods for drawing statistical inferences from texts and transcripts (pp. 9-31). Mahwah, NJ: Lawrence Erlbaum. 
Sin, L. Y. M., Cheung, G. W. H., \& Lee, R. (1999). Methodology in crosscultural consumer research: A review and critical assessment. Journal of International Consumer Marketing, 11, 75-96.

Williams, B. C., \& Plouffe, C. R. (2007). Assessing the evolution of sales knowledge: A 20-year content analysis. Industrial Marketing Management, 36, 408-419.

Workman, J. P., Jr. (1993). Marketing's limited role in new product development in one computer systems firm. Journal of Marketing Research, 30(4), 405-421. 
Annex

Table A1: Articles by journal and journal rating

\begin{tabular}{lrrl}
\hline Journal name & No. & Percent & Rating \\
\hline Journal of Corporate Finance & 21 & 12 & A \\
Journal of Banking and Finance & 66 & 39 & A \\
Journal of International Money and Finance & 2 & 1 & A \\
International Journal of Industrial & 3 & 2 & A \\
Organization & & & \\
Long-Range Planning & 1 & 1 & A \\
Research Policy & 4 & 2 & A \\
Journal of Financial Economics & 19 & 11 & A+ \\
International Business Review & 12 & 7 & B \\
International Financial Markets, Institutions & 3 & 2 & B \\
and Money & & & \\
Journal of World Business & 7 & 4 & B \\
Journal of International Management & 6 & 4 & B \\
European Management Journal & 4 & 2 & B \\
International Review of Financial Analysis & 4 & 2 & B \\
Journal of Accounting and Public Policy & 1 & 1 & B \\
Scandinavian Journal of Management & 4 & 2 & B \\
Journal of Asian Economics & 3 & 2 & Not rated \\
Telecommunications Policy & 1 & 1 & Not rated \\
Journal of Multinational Financial & 1 & 1 & Not rated \\
Management & 1 & 1 & Not \\
Quarterly Review of Economics and Finance & 1 & 1 & Not rated \\
Global Finance Journal & 4 & 2 & Not rated \\
Journal of Economics and Business & 1 & 1 & Not rated \\
Journal of Energy, Finance and & 1 & 1 & Not \\
Development & & & reported \\
Journal of Air Transport Management & & & \\
Total & & & \\
\hline
\end{tabular}

Source: Erasmus Journal Listing, 1 April 2012. 
Figure A1: Authorship type with respect to journal rating

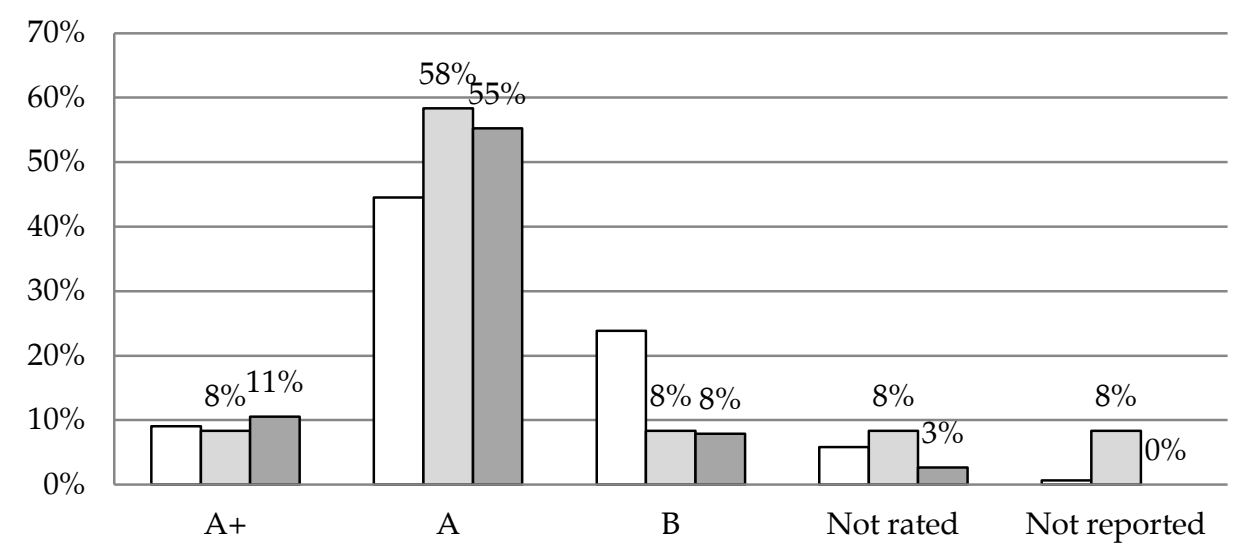

$\square$ Academics $\quad \square$ Practitioners $\quad \square$ Academic-practioner collaborations

Figure A2: Trends in discipline

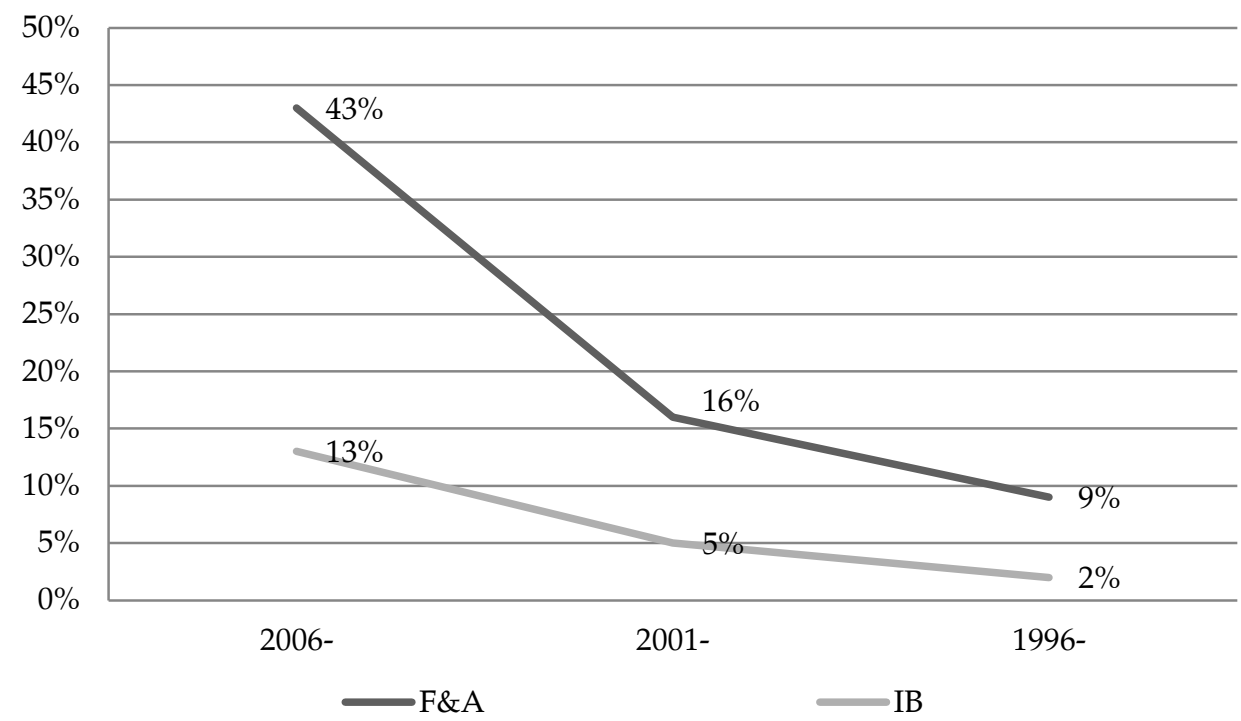


Figure A3: Trends in discipline with respect to journal rating

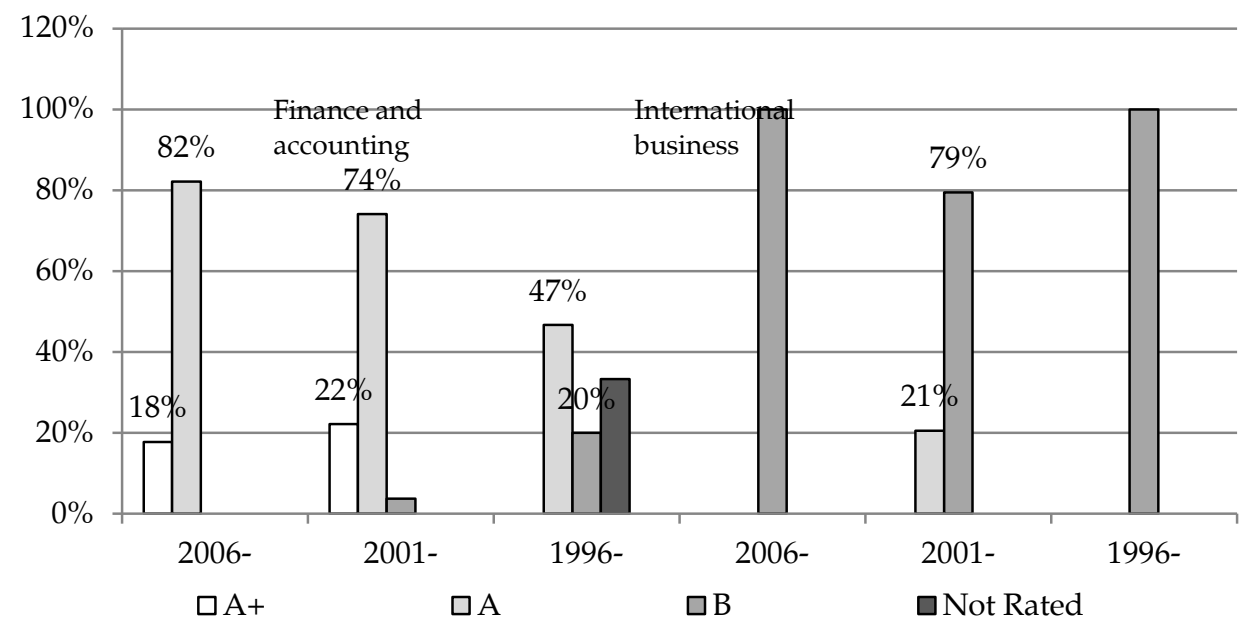

Figure A4: Trends in authors per study with respect to region studied

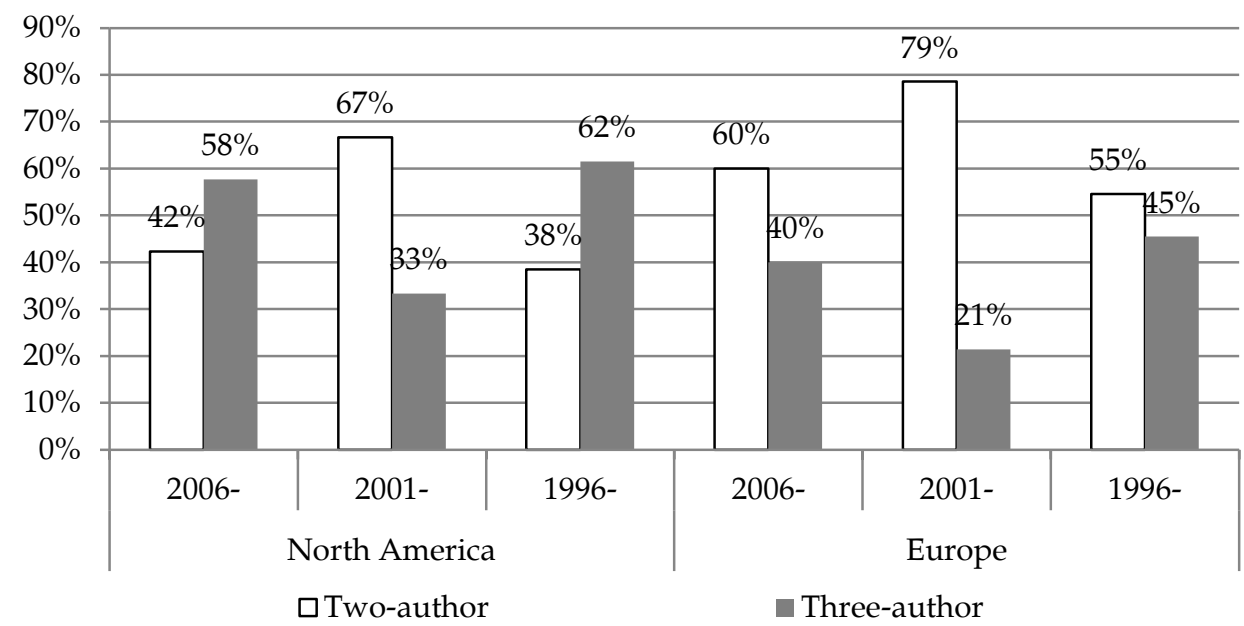


Figure A5: Overall distribution of data sources

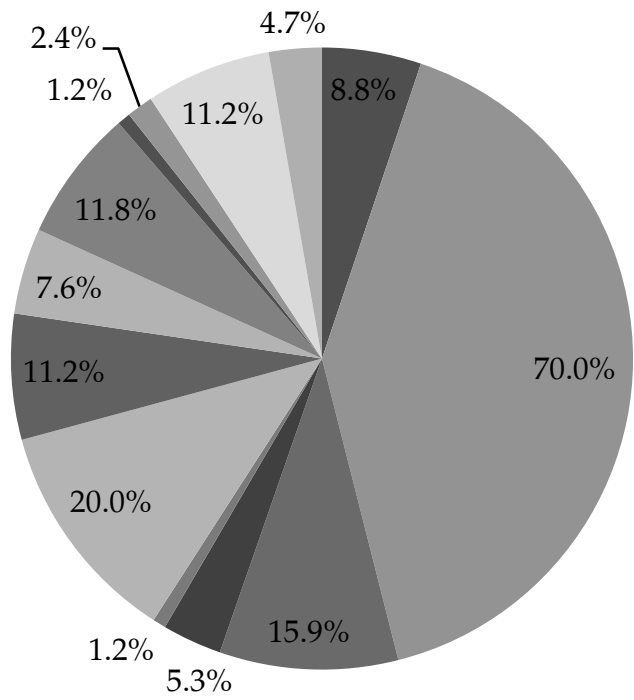

- NR

- Databases (reported)

- Official (published) statistics

- International organizations

- Individuals/experts

- Indexes (FTSE/NYSE/NASDAQ/S\&P)

- Financial newspapers/magazines

- Consulting firms (Moody's Credit/KPMG/Fitch)

- Firm-level data (corporate documents/annual reports/handbooks)

- Popular academic literature

Websites

Banks

- Govt. institutions 
Figure A6: Trends in data sources used

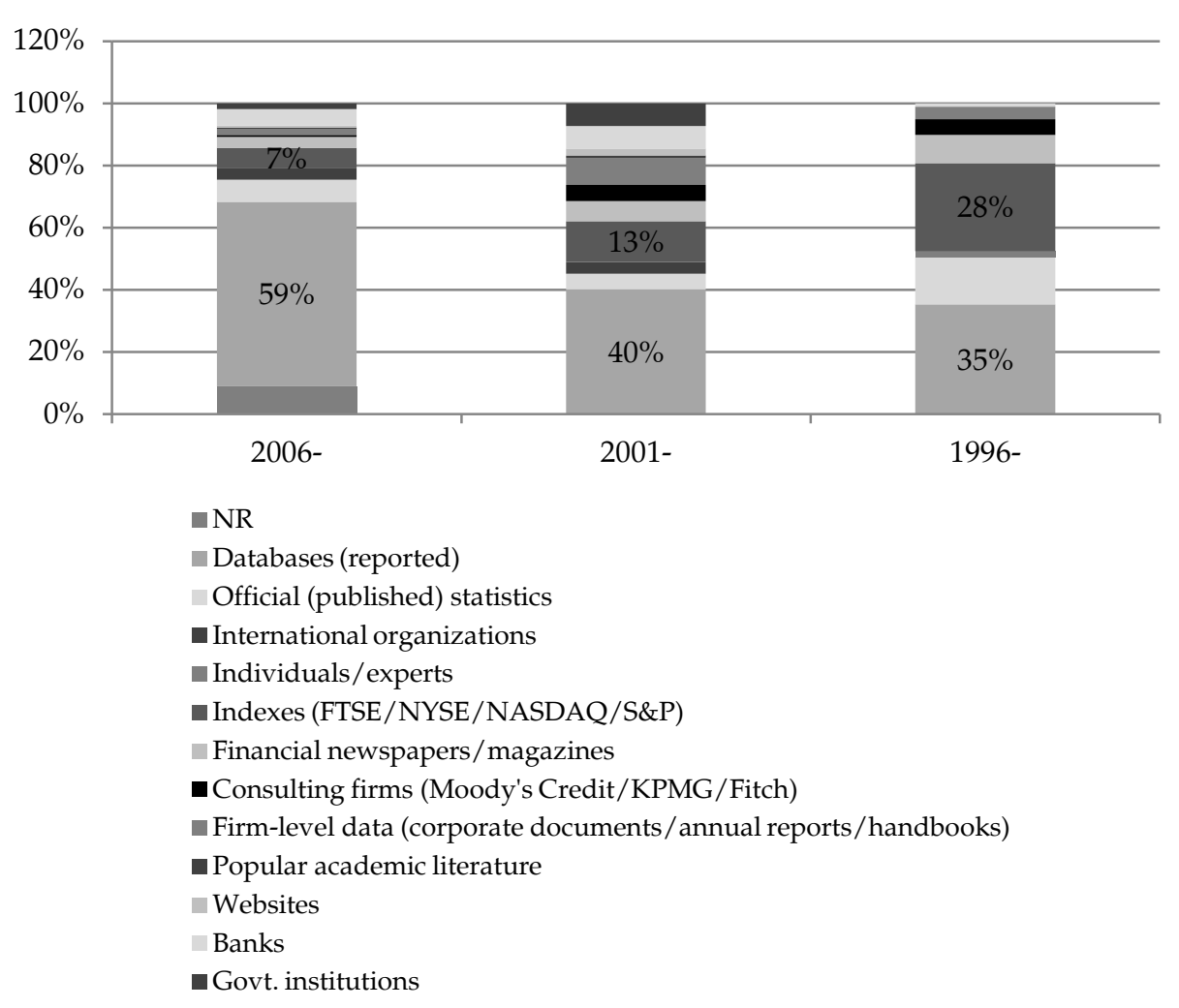

Figure A7: Overall distribution of statistical techniques

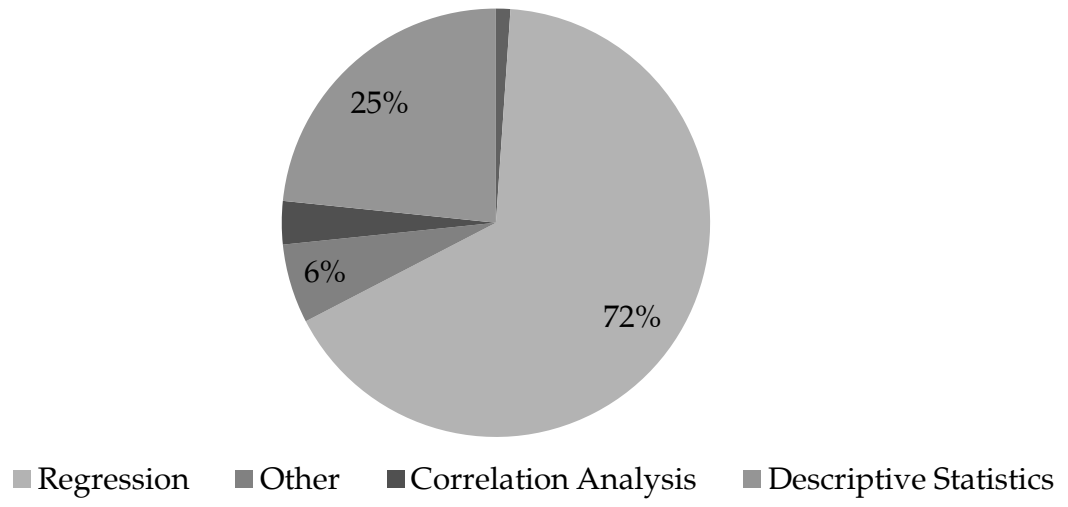


Figure A8: Trends in statistical techniques used

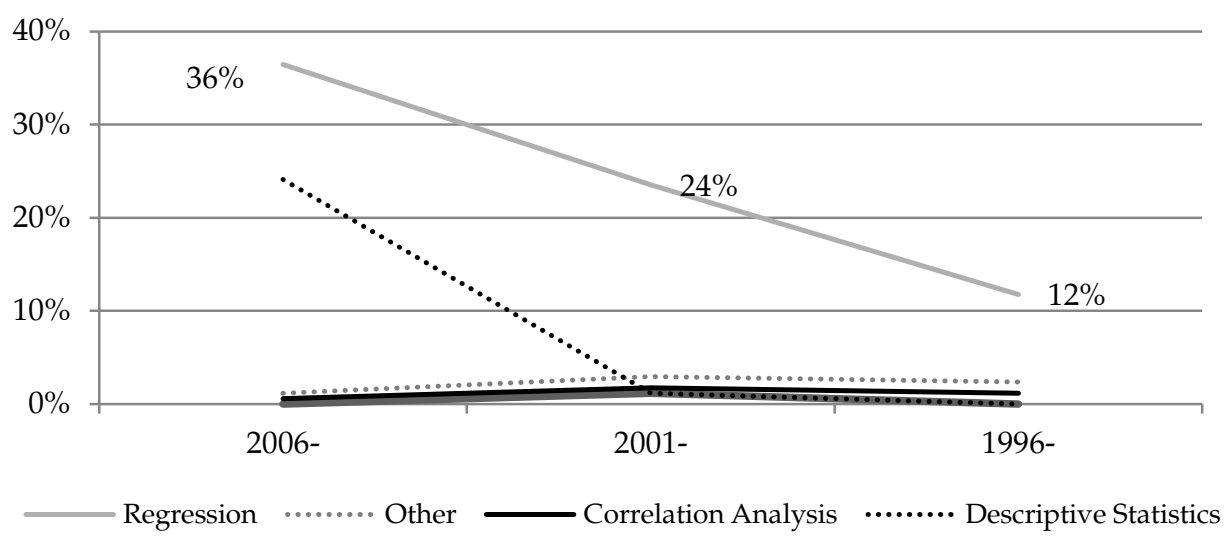

Figure A9: Trends in financial institutions with respect to region

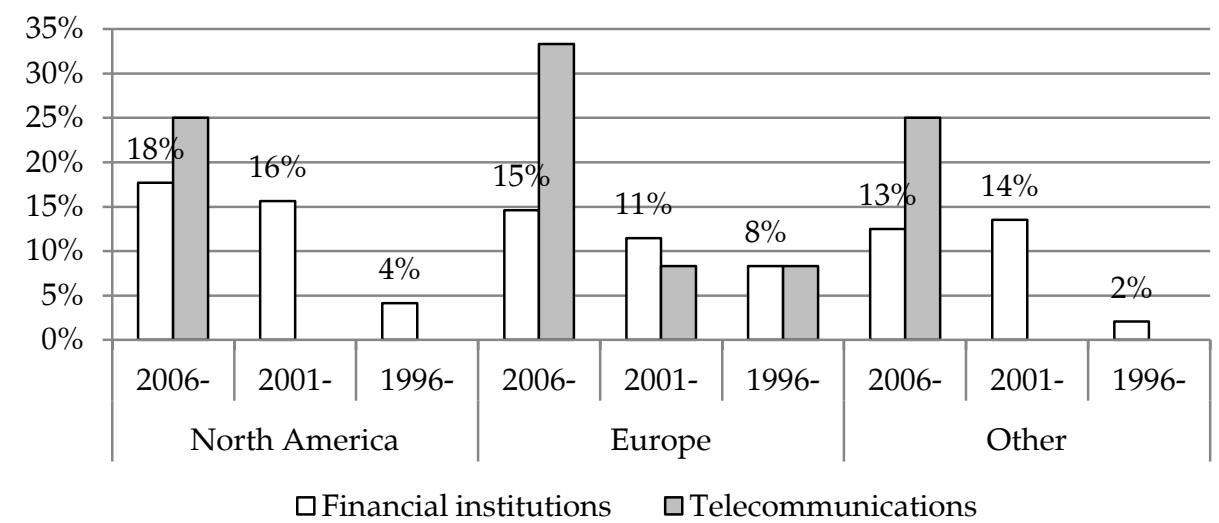

Figure A10: Trends in manufacturing industry studied with respect to region

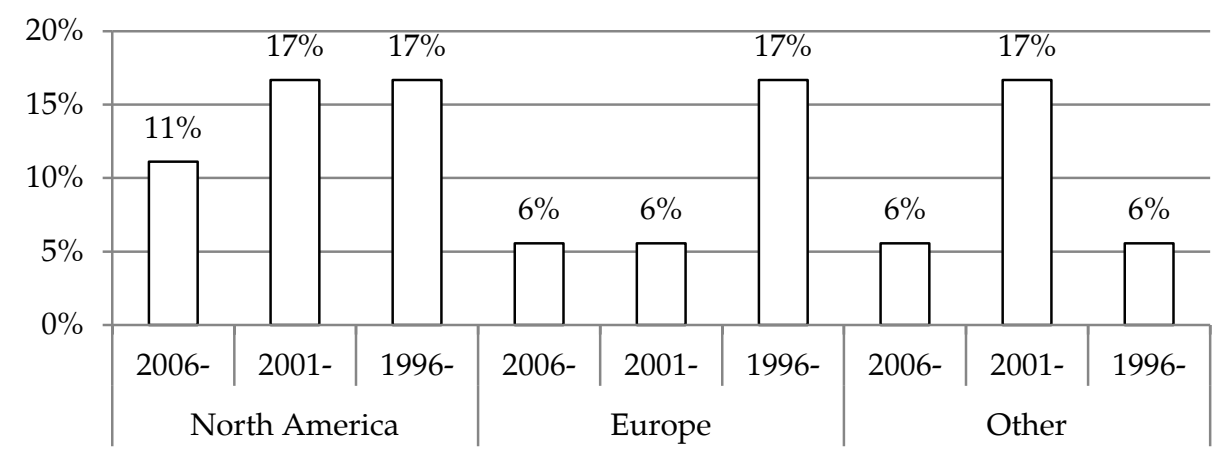

$\square$ Manufacturing firms 
Table A2: Publication trends in conceptual quantitative studies

\begin{tabular}{|c|c|c|c|c|c|c|c|c|c|c|c|c|c|c|c|c|}
\hline \multirow[b]{3}{*}{ Trend } & \multirow[b]{3}{*}{ Total } & & & & & & & \multicolumn{9}{|c|}{ By year within region } \\
\hline & & \multicolumn{3}{|c|}{ By year } & \multicolumn{3}{|c|}{ By region } & \multicolumn{3}{|c|}{ NA } & \multicolumn{3}{|c|}{ Europe } & \multicolumn{3}{|c|}{ Other } \\
\hline & & 2006 & 2001 & 1996 & NA & Europe & Other & 2006 & 2001 & 1996 & 2006 & 2001 & 1996 & 2006 & 2001 & 1996 \\
\hline Total studies & 170 & 102 & 42 & 26 & 68 & 71 & 51 & 31 & 24 & 13 & 34 & 22 & 15 & 23 & 22 & 6 \\
\hline \multicolumn{17}{|l|}{ Authorship type } \\
\hline Academics & $76 \%$ & $46 \%$ & $17 \%$ & $14 \%$ & $33 \%$ & $29 \%$ & $22 \%$ & $15 \%$ & $10 \%$ & $8 \%$ & $15 \%$ & $8 \%$ & $7 \%$ & $10 \%$ & $8 \%$ & $4 \%$ \\
\hline Practitioners & $6 \%$ & $4 \%$ & $2 \%$ & $1 \%$ & $4 \%$ & $2 \%$ & $3 \%$ & $1 \%$ & $1 \%$ & $0 \%$ & $1 \%$ & $1 \%$ & $1 \%$ & $1 \%$ & $2 \%$ & $0 \%$ \\
\hline Collaboration & $17 \%$ & $11 \%$ & $5 \%$ & $1 \%$ & $5 \%$ & $11 \%$ & $5 \%$ & $2 \%$ & $3 \%$ & $0 \%$ & $5 \%$ & $5 \%$ & $1 \%$ & $2 \%$ & $3 \%$ & $0 \%$ \\
\hline \multicolumn{17}{|l|}{ Authors per study } \\
\hline Single author & $16 \%$ & $8 \%$ & $5 \%$ & $3 \%$ & $6 \%$ & $8 \%$ & $4 \%$ & $2 \%$ & $4 \%$ & $0 \%$ & $2 \%$ & $4 \%$ & $2 \%$ & $8 \%$ & $3 \%$ & $0 \%$ \\
\hline Two authors & $46 \%$ & $27 \%$ & $12 \%$ & $6 \%$ & $15 \%$ & $21 \%$ & $14 \%$ & $6 \%$ & $6 \%$ & $3 \%$ & $11 \%$ & $6 \%$ & $4 \%$ & $8 \%$ & $5 \%$ & $1 \%$ \\
\hline Three authors & $35 \%$ & $24 \%$ & $5 \%$ & $6 \%$ & $16 \%$ & $12 \%$ & $10 \%$ & $9 \%$ & $3 \%$ & $5 \%$ & $7 \%$ & $2 \%$ & $3 \%$ & $5 \%$ & $3 \%$ & $3 \%$ \\
\hline Four or more authors & $4 \%$ & $1 \%$ & $2 \%$ & $0 \%$ & $2 \%$ & $2 \%$ & $3 \%$ & $1 \%$ & $2 \%$ & $0 \%$ & $1 \%$ & $1 \%$ & $0 \%$ & $1 \%$ & $2 \%$ & $0 \%$ \\
\hline \multicolumn{17}{|l|}{ Journals (highest-rated) } \\
\hline Journal of Banking and Finance & $39 \%$ & $25 \%$ & $10 \%$ & $4 \%$ & $13 \%$ & $16 \%$ & $11 \%$ & $6 \%$ & $5 \%$ & $2 \%$ & $9 \%$ & $5 \%$ & $2 \%$ & $5 \%$ & $5 \%$ & $1 \%$ \\
\hline Journal of Corporate Finance & $12 \%$ & $10 \%$ & $2 \%$ & $1 \%$ & $5 \%$ & $4 \%$ & $4 \%$ & $4 \%$ & $1 \%$ & $0 \%$ & $4 \%$ & $0 \%$ & $0 \%$ & $2 \%$ & $1 \%$ & $0 \%$ \\
\hline Journal of Financial Economics & $11 \%$ & $8 \%$ & $4 \%$ & $0 \%$ & $8 \%$ & $3 \%$ & $2 \%$ & $5 \%$ & $2 \%$ & $0 \%$ & $2 \%$ & $1 \%$ & $0 \%$ & $1 \%$ & $1 \%$ & $0 \%$ \\
\hline Journal of World Business & $4 \%$ & $4 \%$ & $0 \%$ & $0 \%$ & $1 \%$ & $1 \%$ & $1 \%$ & $1 \%$ & $0 \%$ & $0 \%$ & $1 \%$ & $0 \%$ & $0 \%$ & $1 \%$ & $0 \%$ & $0 \%$ \\
\hline International Business Review & $7 \%$ & $5 \%$ & $2 \%$ & $0 \%$ & $1 \%$ & $4 \%$ & $3 \%$ & $0 \%$ & $1 \%$ & $0 \%$ & $3 \%$ & $1 \%$ & $0 \%$ & $1 \%$ & $2 \%$ & $0 \%$ \\
\hline Others & $26 \%$ & $8 \%$ & $7 \%$ & $11 \%$ & $14 \%$ & $15 \%$ & $11 \%$ & $2 \%$ & $6 \%$ & $6 \%$ & $2 \%$ & $6 \%$ & $7 \%$ & $4 \%$ & $4 \%$ & $3 \%$ \\
\hline \multicolumn{17}{|l|}{ Journal rating } \\
\hline$A+$ & $11 \%$ & $7.6 \%$ & $3.5 \%$ & $0.0 \%$ & $8 \%$ & $3 \%$ & $2 \%$ & $5 \%$ & $2 \%$ & $0 \%$ & $2 \%$ & $1 \%$ & $0 \%$ & $1 \%$ & $1 \%$ & $0 \%$ \\
\hline A & $57 \%$ & $35 \%$ & $16 \%$ & $6 \%$ & $22 \%$ & $25 \%$ & $18 \%$ & $11 \%$ & $9 \%$ & $2 \%$ & $12 \%$ & $9 \%$ & $4 \%$ & $8 \%$ & $9 \%$ & $1 \%$ \\
\hline B & $24 \%$ & $15 \%$ & $5 \%$ & $4 \%$ & $8 \%$ & $10 \%$ & $7 \%$ & $2 \%$ & $3 \%$ & $2 \%$ & $6 \%$ & $2 \%$ & $2 \%$ & $4 \%$ & $3 \%$ & $1 \%$ \\
\hline Not rated & $6 \%$ & $2 \%$ & $1 \%$ & $4 \%$ & $3 \%$ & $3 \%$ & $4 \%$ & $0 \%$ & $0 \%$ & $3 \%$ & $0 \%$ & $1 \%$ & $2 \%$ & $2 \%$ & $0 \%$ & $2 \%$ \\
\hline
\end{tabular}




\begin{tabular}{|c|c|c|c|c|c|c|c|c|c|c|c|c|c|c|c|c|}
\hline \multirow[b]{3}{*}{ Trend } & \multirow[b]{3}{*}{ Total } & \multirow{2}{*}{\multicolumn{3}{|c|}{ By year }} & \multirow{2}{*}{\multicolumn{3}{|c|}{ By region }} & \multicolumn{9}{|c|}{ By year within region } \\
\hline & & & & & & & & \multicolumn{3}{|c|}{ NA } & \multicolumn{3}{|c|}{ Europe } & \multicolumn{3}{|c|}{ Other } \\
\hline & & 2006 & 2001 & 1996 & NA & Europe & Other & 2006 & 2001 & 1996 & 2006 & 2001 & 1996 & 2006 & 2001 & 1996 \\
\hline Not reported & $1 \%$ & $0 \%$ & $0 \%$ & $1 \%$ & $0 \%$ & $1 \%$ & $0 \%$ & $0 \%$ & $0 \%$ & $0 \%$ & $0 \%$ & $0 \%$ & $1 \%$ & $2 \%$ & $0 \%$ & $0 \%$ \\
\hline \multicolumn{17}{|l|}{ Location of authors } \\
\hline North America & $61 \%$ & $34 \%$ & $16 \%$ & $11 \%$ & $29 \%$ & $22 \%$ & $16 \%$ & $11 \%$ & $11 \%$ & $7 \%$ & $11 \%$ & $0 \%$ & $22 \%$ & $5 \%$ & $8 \%$ & $13 \%$ \\
\hline Europe & $38 \%$ & $25 \%$ & $9 \%$ & $4 \%$ & $11 \%$ & $38 \%$ & $10 \%$ & $5 \%$ & $0 \%$ & $1 \%$ & $0 \%$ & $0 \%$ & $4 \%$ & $6 \%$ & $4 \%$ & $9 \%$ \\
\hline Other & $18 \%$ & $18 \%$ & $0 \%$ & $0 \%$ & $6 \%$ & $0 \%$ & $9 \%$ & $5 \%$ & $0 \%$ & $1 \%$ & $5 \%$ & $0 \%$ & $5 \%$ & $6 \%$ & $4 \%$ & $8 \%$ \\
\hline \multicolumn{17}{|l|}{ No. of author's countries } \\
\hline 1 & $67 \%$ & $8 \%$ & $20 \%$ & $12 \%$ & $29 \%$ & $25 \%$ & $19 \%$ & $12 \%$ & $11 \%$ & $6 \%$ & $9 \%$ & $9 \%$ & $6 \%$ & $1 \%$ & $3 \%$ & $2 \%$ \\
\hline 2 & $30 \%$ & $27 \%$ & $5 \%$ & $4 \%$ & $11 \%$ & $15 \%$ & $10 \%$ & $6 \%$ & $3 \%$ & $2 \%$ & $9 \%$ & $4 \%$ & $2 \%$ & $5 \%$ & $5 \%$ & $1 \%$ \\
\hline 3 & $3 \%$ & $24 \%$ & $0 \%$ & $0 \%$ & $1 \%$ & $1 \%$ & $1 \%$ & $1 \%$ & $0 \%$ & $0 \%$ & $1 \%$ & $0 \%$ & $0 \%$ & $7 \%$ & $3 \%$ & $0 \%$ \\
\hline 4 or more & $0 \%$ & $1 \%$ & $0 \%$ & $0 \%$ & $0 \%$ & $0 \%$ & $0 \%$ & $0 \%$ & $0 \%$ & $0 \%$ & $0 \%$ & $0 \%$ & $0 \%$ & $0 \%$ & $2 \%$ & $0 \%$ \\
\hline \multicolumn{17}{|l|}{ Discipline } \\
\hline Finance and accounting & $68 \%$ & $43 \%$ & $16 \%$ & $9 \%$ & $30 \%$ & $25 \%$ & $18 \%$ & $16 \%$ & $8 \%$ & $6 \%$ & $14 \%$ & $7 \%$ & $4 \%$ & $10 \%$ & $7 \%$ & $2 \%$ \\
\hline $\begin{array}{l}\text { Organizational } \\
\text { behavior/organizational studies, } \\
\text { human resource management, } \\
\text { industrial relations }\end{array}$ & $2 \%$ & $0 \%$ & $1 \%$ & $1 \%$ & $1 \%$ & $2 \%$ & $1 \%$ & $0 \%$ & $1 \%$ & $0 \%$ & $0 \%$ & $1 \%$ & $1 \%$ & $0 \%$ & $1 \%$ & $0 \%$ \\
\hline Gen. and strat. & $1 \%$ & $0 \%$ & $1 \%$ & $0 \%$ & $1 \%$ & $1 \%$ & $1 \%$ & $0 \%$ & $1 \%$ & $0 \%$ & $0 \%$ & $0 \%$ & $0 \%$ & $0 \%$ & $0 \%$ & $0 \%$ \\
\hline Economics & $5 \%$ & $1 \%$ & $1 \%$ & $2 \%$ & $2 \%$ & $4 \%$ & $3 \%$ & $0 \%$ & $1 \%$ & $1 \%$ & $0 \%$ & $1 \%$ & $2 \%$ & $1 \%$ & $1 \%$ & $1 \%$ \\
\hline International business & $21 \%$ & $13 \%$ & $5 \%$ & $2 \%$ & $0 \%$ & $0 \%$ & $0 \%$ & $2 \%$ & $4 \%$ & $1 \%$ & $5 \%$ & $2 \%$ & $2 \%$ & $2 \%$ & $4 \%$ & $0 \%$ \\
\hline $\begin{array}{l}\text { Management information } \\
\text { systems, knowledge management }\end{array}$ & $1 \%$ & $0 \%$ & $1 \%$ & $0 \%$ & $0 \%$ & $1 \%$ & $0 \%$ & $0 \%$ & $0 \%$ & $0 \%$ & $0 \%$ & $1 \%$ & $0 \%$ & $0 \%$ & $0 \%$ & $0 \%$ \\
\hline
\end{tabular}

Note: Category counts that exceed the column total are not mutually exclusive. 
Table A3: Methodological trends in conceptual quantitative studies

\begin{tabular}{|c|c|c|c|c|c|c|c|c|c|c|c|c|c|c|c|c|}
\hline & \multirow[b]{3}{*}{ Total } & & & & & & & \multicolumn{9}{|c|}{ By year within region } \\
\hline & & \multicolumn{3}{|c|}{ By year } & \multicolumn{3}{|c|}{ By region } & \multicolumn{3}{|c|}{ North America } & \multicolumn{3}{|c|}{ Europe } & \multicolumn{3}{|c|}{ Other } \\
\hline & & 2006- & 2001- & 1996- & N. Am. & Eur. & Oth. & 2006- & 2001- & 1996- & 2006- & 2001- & 1996- & 2006- & 2001- & 1996- \\
\hline Total studies & 170 & 102 & 42 & 26 & 68 & 71 & 50 & 31 & 24 & 13 & 34 & 22 & 15 & 22 & 22 & 6 \\
\hline Total studies & $100 \%$ & $60 \%$ & $25 \%$ & $15 \%$ & $40 \%$ & $42 \%$ & $31 \%$ & $18 \%$ & $15 \%$ & $8 \%$ & $20 \%$ & $13 \%$ & $9 \%$ & $15 \%$ & $13 \%$ & $3 \%$ \\
\hline Empirical quantitative & $0 \%$ & $0 \%$ & $0 \%$ & $0 \%$ & $0 \%$ & $0 \%$ & $0 \%$ & $0 \%$ & $0 \%$ & $0 \%$ & $0 \%$ & $0 \%$ & $0 \%$ & $0 \%$ & $0 \%$ & $0 \%$ \\
\hline Empirical qualitative & $0 \%$ & $0 \%$ & $0 \%$ & $0 \%$ & $0 \%$ & $0 \%$ & $0 \%$ & $0 \%$ & $0 \%$ & $0 \%$ & $0 \%$ & $0 \%$ & $0 \%$ & $0 \%$ & $0 \%$ & $0 \%$ \\
\hline Conceptual qualitative & $0 \%$ & $0 \%$ & $0 \%$ & $0 \%$ & $0 \%$ & $0 \%$ & $0 \%$ & $0 \%$ & $0 \%$ & $0 \%$ & $0 \%$ & $0 \%$ & $0 \%$ & $0 \%$ & $0 \%$ & $0 \%$ \\
\hline Conceptual quantitative & $100 \%$ & $60 \%$ & $25 \%$ & $15 \%$ & $40 \%$ & $42 \%$ & $31 \%$ & $18 \%$ & $15 \%$ & $8 \%$ & $20 \%$ & $13 \%$ & $9 \%$ & $15 \%$ & $13 \%$ & $3 \%$ \\
\hline \multicolumn{17}{|l|}{ Data source } \\
\hline Not reported & $9 \%$ & $9 \%$ & $0 \%$ & $0 \%$ & $1 \%$ & $2 \%$ & $2 \%$ & $1 \%$ & $0 \%$ & $0 \%$ & $2 \%$ & $0 \%$ & $0 \%$ & $2 \%$ & $0 \%$ & $0 \%$ \\
\hline Databases (reported) & $70 \%$ & $39 \%$ & $18 \%$ & $13 \%$ & $34 \%$ & $30 \%$ & $21 \%$ & $15 \%$ & $11 \%$ & $8 \%$ & $13 \%$ & $10 \%$ & $7 \%$ & $8 \%$ & $9 \%$ & $4 \%$ \\
\hline Official statistics & $16 \%$ & $6 \%$ & $4 \%$ & $6 \%$ & $9 \%$ & $8 \%$ & $7 \%$ & $1 \%$ & $2 \%$ & $5 \%$ & $2 \%$ & $2 \%$ & $3 \%$ & $1 \%$ & $3 \%$ & $3 \%$ \\
\hline International organizations & $5 \%$ & $3 \%$ & $2 \%$ & $0 \%$ & $1 \%$ & $3 \%$ & $2 \%$ & $0 \%$ & $1 \%$ & $0 \%$ & $1 \%$ & $2 \%$ & $0 \%$ & $1 \%$ & $1 \%$ & $0 \%$ \\
\hline Experts & $1 \%$ & $0 \%$ & $0 \%$ & $1 \%$ & $1 \%$ & $1 \%$ & $0 \%$ & $0 \%$ & $0 \%$ & $1 \%$ & $0 \%$ & $0 \%$ & $1 \%$ & $0 \%$ & $0 \%$ & $0 \%$ \\
\hline Indexes & $20 \%$ & $4 \%$ & $8 \%$ & $9 \%$ & $9 \%$ & $9 \%$ & $8 \%$ & $1 \%$ & $4 \%$ & $5 \%$ & $1 \%$ & $4 \%$ & $5 \%$ & $1 \%$ & $5 \%$ & $2 \%$ \\
\hline Financial magazines & $11 \%$ & $2 \%$ & $4 \%$ & $5 \%$ & $6 \%$ & $6 \%$ & $6 \%$ & $2 \%$ & $2 \%$ & $2 \%$ & $1 \%$ & $2 \%$ & $4 \%$ & $2 \%$ & $3 \%$ & $1 \%$ \\
\hline Consulting firms & $8 \%$ & $1 \%$ & $4 \%$ & $3 \%$ & $4 \%$ & $4 \%$ & $4 \%$ & $0 \%$ & $2 \%$ & $1 \%$ & $0 \%$ & $2 \%$ & $2 \%$ & $1 \%$ & $2 \%$ & $1 \%$ \\
\hline Firm-level data & $12 \%$ & $2 \%$ & $7 \%$ & $2 \%$ & $3 \%$ & $5 \%$ & $4 \%$ & $0 \%$ & $3 \%$ & $0 \%$ & $1 \%$ & $2 \%$ & $2 \%$ & $0 \%$ & $4 \%$ & $0 \%$ \\
\hline Popular literature & $1 \%$ & $1 \%$ & $1 \%$ & $0 \%$ & $1 \%$ & $1 \%$ & $1 \%$ & $0 \%$ & $1 \%$ & $0 \%$ & $1 \%$ & $1 \%$ & $0 \%$ & $0 \%$ & $1 \%$ & $0 \%$ \\
\hline Websites & $2 \%$ & $1 \%$ & $2 \%$ & $0 \%$ & $1 \%$ & $2 \%$ & $1 \%$ & $0 \%$ & $1 \%$ & $0 \%$ & $1 \%$ & $1 \%$ & $0 \%$ & $1 \%$ & $1 \%$ & $0 \%$ \\
\hline Banks & $11 \%$ & $2 \%$ & $6 \%$ & $1 \%$ & $4 \%$ & $4 \%$ & $7 \%$ & $0 \%$ & $4 \%$ & $0 \%$ & $1 \%$ & $3 \%$ & $1 \%$ & $3 \%$ & $4 \%$ & $0 \%$ \\
\hline Government institutions & $5 \%$ & $2 \%$ & $3 \%$ & $0 \%$ & $3 \%$ & $1 \%$ & $3 \%$ & $1 \%$ & $2 \%$ & $0 \%$ & $0 \%$ & $1 \%$ & $0 \%$ & $1 \%$ & $2 \%$ & $0 \%$ \\
\hline
\end{tabular}




\begin{tabular}{|c|c|c|c|c|c|c|c|c|c|c|c|c|c|c|c|c|}
\hline & \multirow[b]{3}{*}{ Total } & \multirow{2}{*}{\multicolumn{3}{|c|}{ By year }} & \multirow{2}{*}{\multicolumn{3}{|c|}{ By region }} & \multicolumn{9}{|c|}{ By year within region } \\
\hline & & & & & & & & \multicolumn{3}{|c|}{ North America } & \multicolumn{3}{|c|}{ Europe } & \multicolumn{3}{|c|}{ Other } \\
\hline & & 2006- & 2001- & 1996- & N. Am. & Eur. & Oth. & 2006- & 2001- & 1996- & 2006- & 2001- & 1996- & 2006- & 2001- & 1996- \\
\hline \multicolumn{17}{|l|}{ Sample size } \\
\hline Not reported & $6 \%$ & $5 \%$ & $1 \%$ & $1 \%$ & $1 \%$ & $2 \%$ & $2 \%$ & $0 \%$ & $1 \%$ & $1 \%$ & $2 \%$ & $0 \%$ & $0 \%$ & $2 \%$ & $0 \%$ & $0 \%$ \\
\hline $0-100$ & $25 \%$ & $11 \%$ & $8 \%$ & $6 \%$ & $8 \%$ & $13 \%$ & $8 \%$ & $2 \%$ & $5 \%$ & $1 \%$ & $4 \%$ & $4 \%$ & $5 \%$ & $3 \%$ & $5 \%$ & $0 \%$ \\
\hline $101-300$ & $21 \%$ & $9 \%$ & $5 \%$ & $6 \%$ & $9 \%$ & $8 \%$ & $7 \%$ & $2 \%$ & $2 \%$ & $5 \%$ & $4 \%$ & $3 \%$ & $2 \%$ & $2 \%$ & $0 \%$ & $5 \%$ \\
\hline $301-500$ & $8 \%$ & $5 \%$ & $1 \%$ & $1 \%$ & $4 \%$ & $4 \%$ & $4 \%$ & $2 \%$ & $1 \%$ & $1 \%$ & $2 \%$ & $1 \%$ & $1 \%$ & $2 \%$ & $1 \%$ & $1 \%$ \\
\hline 501 and above & $40 \%$ & $29 \%$ & $9 \%$ & $2 \%$ & $18 \%$ & $15 \%$ & $11 \%$ & $11 \%$ & $6 \%$ & $1 \%$ & $8 \%$ & $5 \%$ & $1 \%$ & $5 \%$ & $4 \%$ & $2 \%$ \\
\hline Population & $1 \%$ & $0 \%$ & $1 \%$ & $0 \%$ & $1 \%$ & $0 \%$ & $1 \%$ & $0 \%$ & $1 \%$ & $0 \%$ & $0 \%$ & $0 \%$ & $0 \%$ & $0 \%$ & $1 \%$ & $0 \%$ \\
\hline \multicolumn{17}{|l|}{ Statistical techniques } \\
\hline Nor reported & $1 \%$ & $0 \%$ & $1 \%$ & $0 \%$ & $1 \%$ & $0 \%$ & $0 \%$ & $1 \%$ & $0 \%$ & $0 \%$ & $0 \%$ & $1 \%$ & $0 \%$ & $0 \%$ & $0 \%$ & $0 \%$ \\
\hline Regression & $72 \%$ & $61 \%$ & $72 \%$ & $36 \%$ & $24 \%$ & $12 \%$ & $33 \%$ & $32 \%$ & $25 \%$ & $12 \%$ & $15 \%$ & $13 \%$ & $6 \%$ & $11 \%$ & $12 \%$ & $10 \%$ \\
\hline Other & $6 \%$ & $2 \%$ & $6 \%$ & $1 \%$ & $3 \%$ & $2 \%$ & $2 \%$ & $4 \%$ & $1 \%$ & $0 \%$ & $1 \%$ & $2 \%$ & $1 \%$ & $0 \%$ & $1 \%$ & $1 \%$ \\
\hline Correlation analysis & $4 \%$ & $1 \%$ & $4 \%$ & $1 \%$ & $2 \%$ & $1 \%$ & $2 \%$ & $1 \%$ & $1 \%$ & $1 \%$ & $1 \%$ & $1 \%$ & $1 \%$ & $0 \%$ & $1 \%$ & $1 \%$ \\
\hline Descriptive statistics & $25 \%$ & $40 \%$ & $25 \%$ & $24 \%$ & $1 \%$ & $0 \%$ & $6 \%$ & $7 \%$ & $6 \%$ & $6 \%$ & $0 \%$ & $0 \%$ & $0 \%$ & $5 \%$ & $1 \%$ & $0 \%$ \\
\hline \multicolumn{17}{|l|}{ Reliability and validity } \\
\hline Reliability not reported & $94 \%$ & $59 \%$ & $21 \%$ & $13 \%$ & $36 \%$ & $38 \%$ & $29 \%$ & $18 \%$ & $11 \%$ & $7 \%$ & $20 \%$ & $11 \%$ & $8 \%$ & $15 \%$ & $11 \%$ & $3 \%$ \\
\hline Reliability reported & $6 \%$ & $1 \%$ & $3 \%$ & $0 \%$ & $4 \%$ & $4 \%$ & $1 \%$ & $1 \%$ & $3 \%$ & $1 \%$ & $0 \%$ & $2 \%$ & $1 \%$ & $0 \%$ & $1 \%$ & $0 \%$ \\
\hline Validity not reported & $92 \%$ & $59 \%$ & $19 \%$ & $14 \%$ & $34 \%$ & $36 \%$ & $27 \%$ & $18 \%$ & $11 \%$ & $6 \%$ & $20 \%$ & $25 \%$ & $8 \%$ & $15 \%$ & $10 \%$ & $2 \%$ \\
\hline Validity reported & $7 \%$ & $1 \%$ & $5 \%$ & $2 \%$ & $6 \%$ & $5 \%$ & $4 \%$ & $1 \%$ & $4 \%$ & $2 \%$ & $0 \%$ & $4 \%$ & $1 \%$ & $0 \%$ & $2 \%$ & $2 \%$ \\
\hline Robustness not reported & $40 \%$ & $18 \%$ & $9 \%$ & $12 \%$ & $15 \%$ & $16 \%$ & $14 \%$ & $5 \%$ & $4 \%$ & $6 \%$ & $5 \%$ & $4 \%$ & $7 \%$ & $6 \%$ & $5 \%$ & $3 \%$ \\
\hline Robustness reported & $59 \%$ & $42 \%$ & $15 \%$ & $3 \%$ & $25 \%$ & $25 \%$ & $17 \%$ & $14 \%$ & $10 \%$ & $1 \%$ & $15 \%$ & $9 \%$ & $2 \%$ & $9 \%$ & $8 \%$ & $0 \%$ \\
\hline \multicolumn{17}{|l|}{ Industry } \\
\hline Not reported & $41 \%$ & $29 \%$ & $7 \%$ & $5 \%$ & $15 \%$ & $15 \%$ & $10 \%$ & $7 \%$ & $3 \%$ & $5 \%$ & $9 \%$ & $4 \%$ & $1 \%$ & $5 \%$ & $3 \%$ & $2 \%$ \\
\hline
\end{tabular}




\begin{tabular}{|c|c|c|c|c|c|c|c|c|c|c|c|c|c|c|c|c|}
\hline & \multirow[b]{3}{*}{ Total } & & & & & & & \multicolumn{9}{|c|}{ By year within region } \\
\hline & & \multicolumn{3}{|c|}{ By year } & \multicolumn{3}{|c|}{ By region } & \multicolumn{3}{|c|}{ North America } & \multicolumn{3}{|c|}{ Europe } & \multicolumn{3}{|c|}{ Other } \\
\hline & & $2006-$ & 2001- & 1996- & N. Am. & Eur. & Oth. & 2006- & 2001- & 1996- & 2006- & 2001- & 1996- & 2006- & 2001- & $1996-$ \\
\hline Financial institutions & $45 \%$ & $26 \%$ & $13 \%$ & $6 \%$ & $21 \%$ & $19 \%$ & $16 \%$ & $10 \%$ & $9 \%$ & $2 \%$ & $8 \%$ & $6 \%$ & $5 \%$ & $7 \%$ & $8 \%$ & $1 \%$ \\
\hline Nonfinancial institutions & $2 \%$ & $1 \%$ & $1 \%$ & $1 \%$ & $0 \%$ & $1 \%$ & $0 \%$ & $0 \%$ & $0 \%$ & $0 \%$ & $0 \%$ & $0 \%$ & $1 \%$ & $0 \%$ & $0 \%$ & $0 \%$ \\
\hline Pharmaceutical & $4 \%$ & $1 \%$ & $2 \%$ & $1 \%$ & $2 \%$ & $2 \%$ & $3 \%$ & $1 \%$ & $1 \%$ & $1 \%$ & $1 \%$ & $1 \%$ & $1 \%$ & $1 \%$ & $2 \%$ & $0 \%$ \\
\hline Technology & $6 \%$ & $2 \%$ & $4 \%$ & $1 \%$ & $2 \%$ & $2 \%$ & $5 \%$ & $2 \%$ & $0 \%$ & $1 \%$ & $1 \%$ & $0 \%$ & $1 \%$ & $2 \%$ & $3 \%$ & $0 \%$ \\
\hline Telecommunications & $4 \%$ & $3 \%$ & $1 \%$ & $1 \%$ & $2 \%$ & $4 \%$ & $2 \%$ & $2 \%$ & $0 \%$ & $0 \%$ & $2 \%$ & $1 \%$ & $1 \%$ & $2 \%$ & $0 \%$ & $0 \%$ \\
\hline Manufacturing & $7 \%$ & $2 \%$ & $2 \%$ & $3 \%$ & $5 \%$ & $3 \%$ & $3 \%$ & $1 \%$ & $2 \%$ & $2 \%$ & $1 \%$ & $1 \%$ & $2 \%$ & $1 \%$ & $2 \%$ & $0 \%$ \\
\hline Oil and petroleum & $5 \%$ & $2 \%$ & $1 \%$ & $2 \%$ & $3 \%$ & $1 \%$ & $3 \%$ & $1 \%$ & $1 \%$ & $1 \%$ & $1 \%$ & $0 \%$ & $1 \%$ & $2 \%$ & $1 \%$ & $0 \%$ \\
\hline Services & $6 \%$ & $2 \%$ & $2 \%$ & $2 \%$ & $3 \%$ & $3 \%$ & $4 \%$ & $1 \%$ & $1 \%$ & $1 \%$ & $1 \%$ & $1 \%$ & $1 \%$ & $1 \%$ & $2 \%$ & $1 \%$ \\
\hline Mining & $2 \%$ & $1 \%$ & $0 \%$ & $1 \%$ & $2 \%$ & $1 \%$ & $1 \%$ & $1 \%$ & $0 \%$ & $1 \%$ & $1 \%$ & $0 \%$ & $1 \%$ & $1 \%$ & $0 \%$ & $0 \%$ \\
\hline Retail & $2 \%$ & $0 \%$ & $1 \%$ & $1 \%$ & $2 \%$ & $1 \%$ & $1 \%$ & $0 \%$ & $1 \%$ & $1 \%$ & $0 \%$ & $1 \%$ & $1 \%$ & $0 \%$ & $1 \%$ & $0 \%$ \\
\hline Other & $4 \%$ & $1 \%$ & $2 \%$ & $1 \%$ & $2 \%$ & $1 \%$ & $2 \%$ & $1 \%$ & $0 \%$ & $1 \%$ & $1 \%$ & $0 \%$ & $1 \%$ & $1 \%$ & $1 \%$ & $0 \%$ \\
\hline \multicolumn{17}{|l|}{ Time horizon } \\
\hline Cross-sectional & $11 \%$ & $6 \%$ & $3 \%$ & $2 \%$ & $4 \%$ & $6 \%$ & $5 \%$ & $1 \%$ & $2 \%$ & $1 \%$ & $2 \%$ & $2 \%$ & $2 \%$ & $2 \%$ & $2 \%$ & $1 \%$ \\
\hline Longitudinal & $88 \%$ & $54 \%$ & $21 \%$ & $14 \%$ & $36 \%$ & $36 \%$ & $25 \%$ & $17 \%$ & $12 \%$ & $7 \%$ & $18 \%$ & $11 \%$ & $7 \%$ & $12 \%$ & $7 \%$ & $5 \%$ \\
\hline \multicolumn{17}{|c|}{ Difference between data collected and published } \\
\hline $0-5$ years & $55 \%$ & $32 \%$ & $13 \%$ & $9 \%$ & $21 \%$ & $26 \%$ & $19 \%$ & $10 \%$ & $8 \%$ & $4 \%$ & $13 \%$ & $8 \%$ & $5 \%$ & $11 \%$ & $5 \%$ & $3 \%$ \\
\hline $5-10$ years & $34 \%$ & $20 \%$ & $9 \%$ & $5 \%$ & $16 \%$ & $12 \%$ & $10 \%$ & $7 \%$ & $5 \%$ & $4 \%$ & $6 \%$ & $4 \%$ & $3 \%$ & $2 \%$ & $3 \%$ & $5 \%$ \\
\hline $10-15$ years & $4 \%$ & $2 \%$ & $2 \%$ & $0 \%$ & $2 \%$ & $1 \%$ & $1 \%$ & $1 \%$ & $1 \%$ & $0 \%$ & $1 \%$ & $1 \%$ & $0 \%$ & $0 \%$ & $1 \%$ & $0 \%$ \\
\hline 15 and above & $1 \%$ & $1 \%$ & $0 \%$ & $0 \%$ & $0 \%$ & $1 \%$ & $0 \%$ & $0 \%$ & $0 \%$ & $0 \%$ & $1 \%$ & $0 \%$ & $0 \%$ & $0 \%$ & $0 \%$ & $0 \%$ \\
\hline \multicolumn{17}{|l|}{ Number of data sources } \\
\hline 1-3 databases & $32 \%$ & $19 \%$ & $9 \%$ & $4 \%$ & $14 \%$ & $15 \%$ & $5 \%$ & $9 \%$ & $4 \%$ & $2 \%$ & $7 \%$ & $5 \%$ & $2 \%$ & $2 \%$ & $2 \%$ & $1 \%$ \\
\hline 3-6 databases & $16 \%$ & $3 \%$ & $8 \%$ & $5 \%$ & $9 \%$ & $6 \%$ & $8 \%$ & $1 \%$ & $5 \%$ & $3 \%$ & $0 \%$ & $4 \%$ & $3 \%$ & $1 \%$ & $3 \%$ & $4 \%$ \\
\hline
\end{tabular}




\begin{tabular}{|c|c|c|c|c|c|c|c|c|c|c|c|c|c|c|c|c|}
\hline & \multirow[b]{3}{*}{ Total } & & & & & & & \multicolumn{9}{|c|}{ By year within region } \\
\hline & & \multicolumn{3}{|c|}{ By year } & \multicolumn{3}{|c|}{ By region } & \multicolumn{3}{|c|}{ North America } & \multicolumn{3}{|c|}{ Europe } & \multicolumn{3}{|c|}{ Other } \\
\hline & & $2006-$ & 2001- & 1996- & N. Am. & Eur. & Oth. & 2006- & 2001- & 1996- & 2006- & 2001- & 1996- & 2006- & 2001- & 1996- \\
\hline 7 databases & $7 \%$ & $1 \%$ & $3 \%$ & $3 \%$ & $5 \%$ & $4 \%$ & $4 \%$ & $0 \%$ & $2 \%$ & $2 \%$ & $1 \%$ & $2 \%$ & $1 \%$ & $1 \%$ & $1 \%$ & $2 \%$ \\
\hline \multicolumn{17}{|c|}{ Number of countries studied } \\
\hline $10-20$ & $11 \%$ & $5 \%$ & $4 \%$ & $3 \%$ & $5 \%$ & $8 \%$ & $6 \%$ & $1 \%$ & $3 \%$ & $2 \%$ & $3 \%$ & $2 \%$ & $3 \%$ & $2 \%$ & $3 \%$ & $1 \%$ \\
\hline $20-30$ & $5 \%$ & $2 \%$ & $3 \%$ & $0 \%$ & $2 \%$ & $4 \%$ & $2 \%$ & $1 \%$ & $1 \%$ & $0 \%$ & $2 \%$ & $2 \%$ & $0 \%$ & $1 \%$ & $1 \%$ & $0 \%$ \\
\hline $30-40$ & $3 \%$ & $1 \%$ & $2 \%$ & $0 \%$ & $2 \%$ & $3 \%$ & $2 \%$ & $0 \%$ & $2 \%$ & $0 \%$ & $1 \%$ & $2 \%$ & $0 \%$ & $1 \%$ & $1 \%$ & $0 \%$ \\
\hline 40 and above & $6 \%$ & $19 \%$ & $1 \%$ & $1 \%$ & $2 \%$ & $3 \%$ & $1 \%$ & $1 \%$ & $1 \%$ & $0 \%$ & $1 \%$ & $1 \%$ & $1 \%$ & $1 \%$ & $0 \%$ & $0 \%$ \\
\hline \multicolumn{17}{|c|}{ Number of years studied } \\
\hline $10-20$ & $24 \%$ & $15 \%$ & $5 \%$ & $4 \%$ & $12 \%$ & $8 \%$ & $7 \%$ & $6 \%$ & $3 \%$ & $2 \%$ & $5 \%$ & $2 \%$ & $1 \%$ & $4 \%$ & $2 \%$ & $1 \%$ \\
\hline $20-30$ & $9 \%$ & $7 \%$ & $2 \%$ & $1 \%$ & $4 \%$ & $2 \%$ & $4 \%$ & $3 \%$ & $1 \%$ & $0 \%$ & $1 \%$ & $1 \%$ & $0 \%$ & $2 \%$ & $2 \%$ & $0 \%$ \\
\hline $30-40$ & $2 \%$ & $2 \%$ & $0 \%$ & $0 \%$ & $0 \%$ & $0 \%$ & $1 \%$ & $0 \%$ & $0 \%$ & $0 \%$ & $0 \%$ & $0 \%$ & $0 \%$ & $1 \%$ & $0 \%$ & $0 \%$ \\
\hline 40 and above & $2 \%$ & $2 \%$ & $1 \%$ & $1 \%$ & $2 \%$ & $3 \%$ & $1 \%$ & $1 \%$ & $1 \%$ & $0 \%$ & $1 \%$ & $1 \%$ & $1 \%$ & $1 \%$ & $0 \%$ & $0 \%$ \\
\hline
\end{tabular}

Note: Category counts that exceed the column total are not mutually exclusive. 